\title{
AN OPTIMIZED PID CONTROLLER FOR DEEP SPACE ANTENNA DC MOTOR POSITION CONTROL USING MODIFIED ARTIFICIAL FISH SWARM ALGORITHM
}

\author{
Jibril Y. ${ }^{1}$, Salawudeen A. T. ${ }^{1}$, Salawu A. ${ }^{2}$, Zainab M. ${ }^{1}$ \\ ${ }^{1}$ Department of Electrical and Computer Engineering, Ahmadu Bello University Zaria, Nigeria \\ ${ }^{2}$ Department of Physics, Federal University Lokoja, Kogi State, Nigeria \\ E-mail: yjibril@abu.edu.ng
}

\begin{abstract}
The aim of the present study is to build an intelligent Proportional-Integral-Derivative (PID) controller for deep space antenna position control using a modified artificial fish swarm optimization algorithm. The PID controller remains the most widely used controller in the engineering industries due to its ease of implementation and minimum requirement of designer's intervention. The performance of the controller depends mainly on the designer's choice of the controller (proportion, integral and derivative) gains. Conventional method may take several hours or even days before the right set of parameters which give the required system specification is obtained. Therefore, this study presents an optimization approach for determining the PID controller parameters for the position control of deep space antenna azimuth using the weighted artificial fish swarm algorithm (wAFSA). Also, the standard AFSA was used to design the PID controller for the comparison. Some MATLAB simulation was performed under different deep space antenna amplifier gain to determine the efficiency of the proposed controller. Simulation results revealed the effectiveness and validity of the proposed optimized PID controller regarding settling time (ST), rise time (RT), overshoot (OS), steady state error (STE) and most significantly minimized the cost.
\end{abstract}

Keywords: PID controller, weighted artificial fish swarm algorithm (wAFSA), deep space antenna.

\section{INTRODUCTION}

Over the years, the development of modern satellites and radar systems has placed a significant importance on control systems with an acceptable and immaculate position in industries and communication communities. Antennas are electrical devices which convert electric energy into radio waves and vice versa [1]. Antenna communicates with spacecraft by sending an uplink command and receiving a downlink information [2]. A deep space antenna azimuth tracking a satellite signal must keep the satellite within its beam-width, not tolose the track [3]. However, for frequencies like the Ka-band, a high and robust tracking efficiency is required. To achieve this efficiency, the antenna in Figure 1 is continuously positioned with the aid of a controller and a drive mechanism. The Proportional-Integral-Derivative (PID) controller is being used widely for this purpose [4-7]. The performance of the PID controller depends largely on the design choice of its tuning parameters. The conventional method of tuning these parameters is time-consuming. In some complex systems, it may take hours or even 
days before the values of these parameters with given design specification is achieved.Therefore, a meta-heuristic optimization algorithm which is inspired by the intelligent behavior of biological system has been employed for tuning the PID controller parameters. These bioinspired algorithms include particle swarm optimization (PSO) [8], artificial bee colony (ABC) [9], firefly algorithm (FFA) [10], ant colony optimization (ACO) [11], bacterial foraging algorithm [12] artificial fish swarm algorithm [13]. Due to improper and constant parameters associated with these algorithms, several researchers have proposed various modifications with the anticipation of addressing their imbalance between exploration and exploitation and a tremendous improvement have been made. Therefore, in the present study, a modified optimization algorithm, which is inspired by the adaptive behavior of a school of fish [14, 15] for the tuning of PID controller parameter has been reported for the position control of the Antenna Positioning System.

\section{ANTENNA AZIMUTH AND MODEL}

A control system is a specifically designed system for getting the required input-output characteristics of a system. Antenna azimuth is one of the systems in the communication industry, which requires an efficient control [16]. The position of the antenna is controlled by gears and feedback potentiometer. This control required the action of a high-level controller capable of position the antenna focus for effective satellite tracking. The system layout of the antenna azimuth is presented in Figure 1.

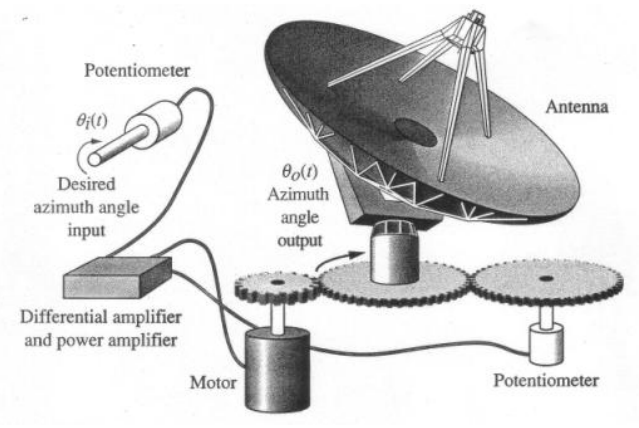

Fig.1. The design of antenna azimuth position control system $[17,3]$ The schematic circuit diagram of the antenna azimuth feedback system with a controller is given in Figure 2.

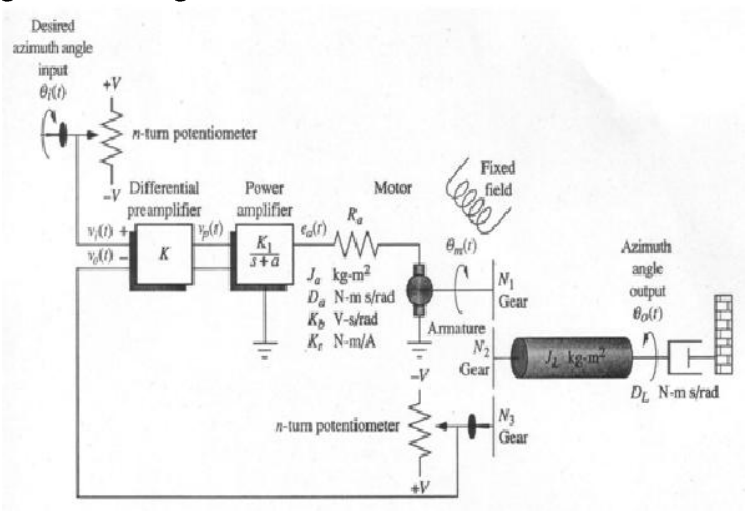

Fig. 2. Schematic Circuit Diagram of Antenna Azimuth

From Figure 2, the objective of the scheme is to obtain the azimuth angle using the input angler displacement of the potentiometer. The potentiometer converted the output angular displacement to a voltage in the feedback path. A differential amplifier is utilized to determine the error signal between the input signal and the output to ensure an appropriate adjustment. Figure 3, shows the antenna azimuth feedback control in the block diagram.

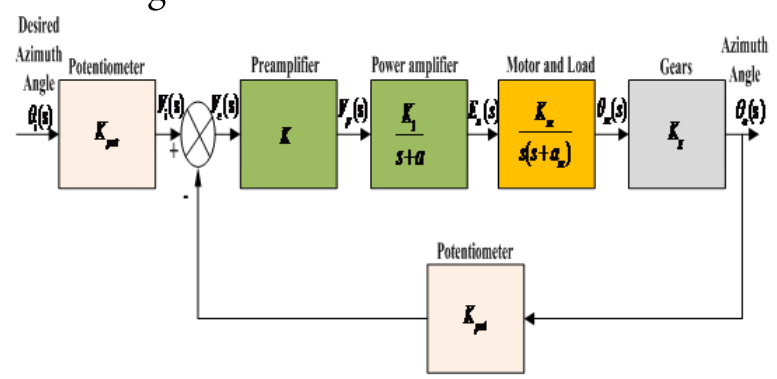

Fig.3. The block diagram of antenna azimuth position control system. 
Notably, the mathematical model of the armature dc servo motor controlling the antenna azimuth already exists in the literature. Therefore, the model reported previously $[18,3]$ is adopted in the present study. The transfer function of the adopted model is given in Eq 1 .

$$
\frac{\theta_{o}(s)}{\theta_{i}(s)}=G(s)=\frac{6.63 K}{s^{3}+101.71 s^{2}+171 s+6.63 K}
$$

Where $\mathrm{K}$ is the amplifier gain. The PID controller whose parameters are tuned using the weighted artificial fish swarm algorithm (wAFSA) [14] is implemented using MATLAB R2015b simulation environment. The implementation procedure is discussed in the following section.

\section{PID TUNING USING WAFSA}

The procedures employed for the PID tuning are discussed below:

\subsection{OBJECTIVE FUNCTION FORMULATION}

At the tuning stage, an objective function which is based on systematic errors were formulated. Recall that the generalize Eq (2) of PID controller is [19-21].

$$
U(t)=K_{p} \times e(t)+\frac{1}{T_{i}} \int_{0}^{t} e(t) d t+T_{d} \frac{d e(t)}{d t}
$$

Where, $\mathrm{K}_{\mathrm{p}}=$ proportional gain, $\mathrm{T}_{\mathrm{i}}=$ integral time, and $T_{d}=$ derivative time. The tracking error which is the difference between the desired output and the actual output is represented. This error is sent to the PID controller, and the controller computes it's integral and derivative gains. The magnitude of the input signal from the controller is determined as follows in $\mathrm{Eq}(3)[20,22]$ :

$$
U(t)_{c}=K_{p} \times|e(t)|+K_{i} \times e(t)+K_{d} \times e(t)
$$

The objective function, the PID performance criteria is formulated as a function of this error (Integral Absolute Error-IAE, Integral of Time Square Errer-ITSE and Integral of Square Error-ISE) as follows:

$$
\begin{aligned}
& I A E=\int_{0}^{\infty}\left|r(t)-y(t) d t=\int_{0}^{\infty}\right| e(t)|d t| \\
& I S E=\int_{0}^{\infty} e^{2}(t) d t \\
& I S E=\int_{0}^{\infty} t \cdot e^{2}(t) d t
\end{aligned}
$$

Eq (4-6) shows a time domain representation of the errors. An optimized value of the PID controller gains can obtain a good system behavior capable of minimizing the performance criteria in the time domain.

\subsection{WAFSA IMPLEMENTATION}

In this study, we modified the preying, swarming and chasing behavior of AFSA reported previously $[14,23,15]$. The basic idea of the wAFSA is to introduce a weighting factor, capable of interactively determining the control (visual distance and step size) parameters at every generation. This idea may minimize the ease at which the standard algorithm gets trapped into local minima by reducing the imbalance between exploration and exploitation. We assume that the problem (PID-parameters) under consideration has Ddimensions and the swarm is initialized with P-population of artificial fishes, such that the state of one artificial fish can be formulated as:

$$
X_{i}=\left(x_{i 1}, x_{i 2}, \ldots ., x_{i D}\right) \text { for } . i=1,2 \ldots \ldots . P
$$

Where $\mathrm{Xi}$ is the status of the fish, which represents the target variable for the problem under consideration [24]. The fitness function of fish in the current position is expressed as $y=f\left(x_{i}\right)$. The Euclidean distance between artificial fish is:

$$
d_{i, j}=\left\|X_{i}-X_{j}\right\|
$$


Where $i, j$ are randomly generated fish.

\subsubsection{Weighted preying}

For the most part the fish senses the region with more food in water by vision, sense and/or communication with neighboring fishes and moves quickly towards that region [25] using synergistic, reconnaissance or stochastic move rule. We assume that the current state of AF is the artificial fish chooses a state randomly within its visual distance such that:

$$
X_{j}=X_{i}+\operatorname{rand}(0,1) \times \text { visual } \times\left(\frac{i t r_{\max }-i t r}{i t r_{\max }}\right)^{n}
$$

If $f\left(X_{j}\right)<f\left(X_{i}\right)$ in the minimum problem, it goes forward a step towards $X_{j}$ in the following direction:

$$
X_{i}^{(t+1)}=X_{i}^{(t)}+\operatorname{rand}(0,1) \times \text { step } \times\left(\frac{i r_{\max }-i t r}{i t r_{\max }}\right)^{n} \times \frac{X_{j}^{(t)}-X_{i}^{(t)}}{\left\|X_{j}^{(t)}-X_{i}^{(t)}\right\|}
$$

$$
\left\|X_{j}^{(t)}-X_{i}^{t}\right\|=\left|\sqrt{\left(\left(X_{j}^{(t)}\right)^{2}-\left(X_{i}^{(t)}\right)^{2}\right)}\right|
$$

If $f\left(X_{j}\right)>f\left(X_{i}\right)$, the artificial fish again selects another state randomly. The artificial fish moves one step randomly as follows if it does not meet the requirement in a given time:

$$
X_{i}^{t+1}=X_{i}^{t}+\operatorname{rand}(0,1) \times \text { step } \times\left(\frac{i t r_{\max }-i t r}{i t r_{\max }}\right)^{n}
$$

\subsubsection{Swarming}

Fish assemble in groups for the safety and survival [26]. Suppose the current state of the artificial fish is $X_{i}$ and $n f$ is the number of companions within the visual distance that is $V=\left\{X_{i} \mid d_{i j} \leq\right.$ visual $\}, n f \neq 0$. Which means set $\mathrm{V}$ is not empty $[14,15]$. Let $X_{c}$ be the center position and $Y_{c}$ is the fitness of $X_{c}$, then

$$
X_{c}=\sum_{j}^{n f} X_{j} / n f \text { and } Y_{c}=f\left(X_{c}\right)
$$

If $n f \times Y_{c}<\delta \times Y_{i}$, and $Y_{c}<Y_{i}$, the artificial fish moves one step forward to the companions' center position as follows [14, 15]:

$X_{i}^{(t+1)}=X_{i}^{(t)}+\operatorname{rand}(0,1) \times \operatorname{step} \times\left(\frac{i t r_{\max }-i t r}{i t r_{\max }}\right)^{n} \times \frac{X_{c}^{(t)}-X_{i}^{(t)}}{\left\|X_{c}^{(t)}-X_{i}^{(t)}\right\|}(14)$

If this is disadvantageous then, it executes the preying behavior $[14,15]$. The crowd factor limits the scale of swarms, and more AF only cluster in the best area [27], which ensures the travel to an optimum location in a wide field [25].

\subsubsection{Chasing}

After a fish finds food, neighboring fish will stream and get to the food. Suppose the current state of the artificial fish is $X_{i}$ and $X_{m}$ is the best AF individual within the visual distance. $\quad Y_{m}=f\left(X_{m}\right) \quad, \quad$ if $\quad Y_{m}<Y_{i}$ and $n f \times Y_{m}<\delta \times Y_{i}$ the artificial fish moves one step towards $X_{m}$ as follows:

$$
X_{i}^{(t+1)}=X_{i}^{(t)}+\operatorname{rand}(0,1) \times \operatorname{step} \times\left(\frac{i t r_{\max }-i t r}{i t r_{\max }}\right)^{n} \times \frac{X_{m}^{(t)}-X_{i}^{(t)}}{\left\|X_{m}^{(t)}-X_{i}^{(t)}\right\|}
$$

If this is disadvantageous then, it executes the behavior of preying. The number of $X_{m}$ 's within the visual distance is $n f$. Chasing accelerates AF moving to better states, andsimultaneously, accelerates AF moving to the global extreme value field from the local extreme values $[25,26]$. In the present study, the developed wAFSA alongside the standard AFSA was applied to the objective function discussed in subsection 3.1 with the aim of minimizing some performance criteria. The performance criteria include: Raise Time (RT), Overshoot (OS), Settling Time (ST), Steady State Error (SSE) and Cost Function. It has been stated that, for a good controller design, these performance criteria primarily the OS and ST should be less than 20\% and 
20 seconds, respectively $[28,23]$. Therefore, the focus of this study is to obtain a performance result that is three times less than these values (Note: this is the papers focus). The block diagram of the proposed PID tuning method is presented in Figure 4.

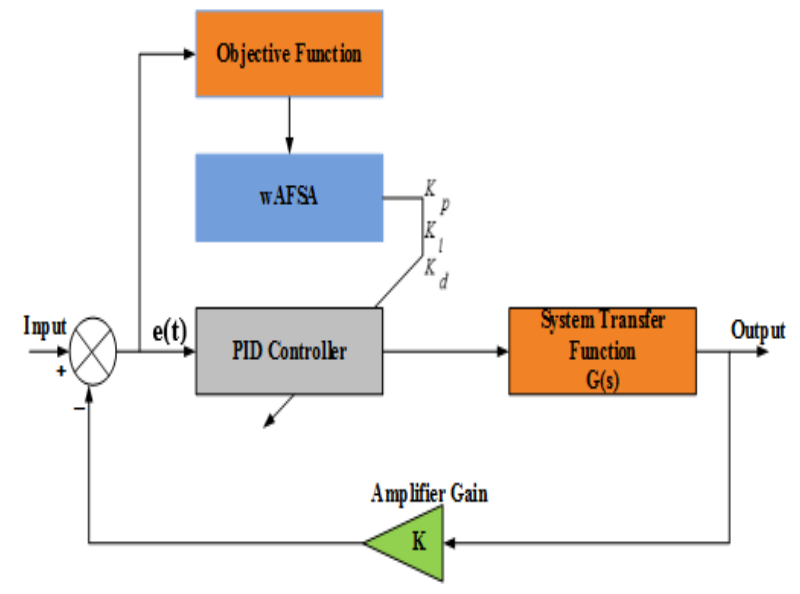

Fig. 4. Implementation of the system using PID Controller

Various studies have reported the detailed information on the implementation of wAFSA [14, 23, 15]. Unlike the conventional method of tuning PID controller, the artificial fish (which in this case are the gains) having unfavorable costs is discarded and with favorable costs is retained in the optimization space. In this study, each wAFSA simulation consists of three artificial fishes (PID gains- $\mathrm{K}_{\mathrm{p}}$, $\mathrm{K}_{\mathrm{i}}$, and $\mathrm{K}_{\mathrm{d}}$ ). This suggests that the search space consists of three dimensions and the artificial fishes must swarm in this space. The flow chart representation of the wAFSA implementation is given in Figure 5.

\section{PARAMETER SETTING AND SIMULATION}

To demonstrate the effectiveness of the proposed method, the responses of the system are analyzed under different preamplifier's gain, K. According to Routh-Herwitz criterion, a system is stable if the value of the gain " $K$ " is within the range of 0-262 [29, 30, $3,21]$.

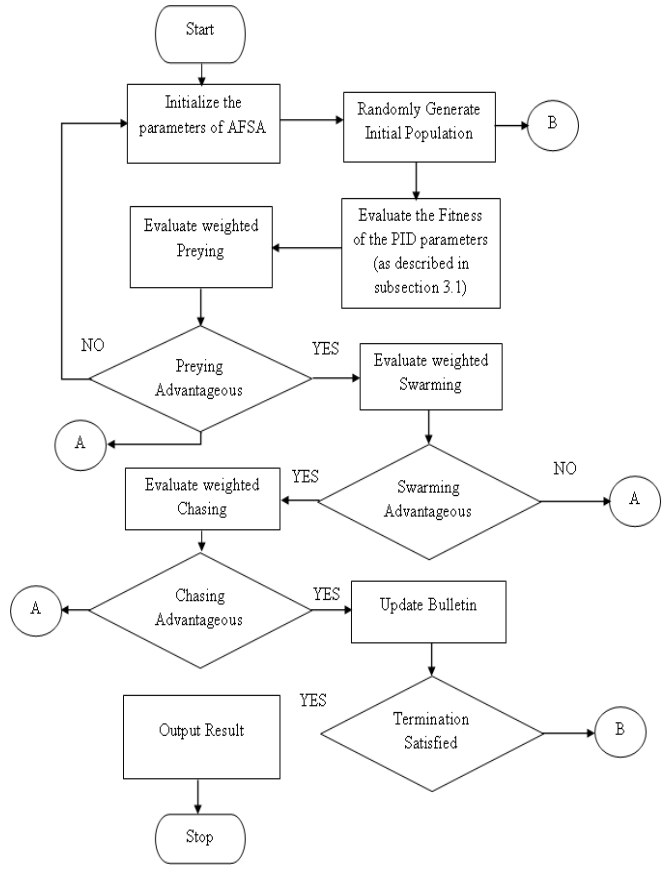

Fig.5. Flow Chart Implementation

Therefore, the performance of the proposed controller is evaluated under a preamplifier gain of 100, 150 and 200, respectively. The choice of the gains was the decision of the authors. Perhaps, the decision can be made alternatively.

\subsection{SiMULATION PARAMETERS}

Although, there is no known standard format to follow in choosing the control parameters of AFSA [26, 14, 31], however for this study the parameters shown in Table 1, were employed for both the algorithms, modified wAFSA and standard AFSA. Notably, these parameters (except search dimension) can be varied under various simulation conditions. In this study, the combination of parameters which gives the best performance was presented. Studies reported the detailed information about the parameters of wAFSA $[14,15]$. The search dimension is determined based on the number of controller parameters that needs to be optimized. In this case, three (3) is synonymous to the $\mathrm{K}_{\mathrm{p}}, \mathrm{K}_{\mathrm{i}}$, and $\mathrm{K}_{\mathrm{d}}$ of the PID controller. 
TABLE 1: SimULATION PARAMETERS

\begin{tabular}{|c|c|c|}
\hline SN & Parameters & Value \\
\hline 1 & Population of Fish & 80 \\
\hline 2 & Search Dimension & 3 \\
\hline 3 & Visual Distance & 5 \\
\hline 4 & Step Size & 0.75 \\
\hline 5 & Crowd factor & 0.25 \\
\hline 6 & Maximum number of iteration & 100 \\
\hline 7 & Preamplifier gain (K) & 100,150, \\
\hline
\end{tabular}

\subsection{SimULATION RESULTS AND DisCUSSION}

This subsection discusses the optimized results acquired for each of the amplifier gained. For an amplifier gain of 100, the response of the system is shown in Figure 6. The optimized PID controller gains and the steady state performance of the system are given in Table 2. Figure 6(a), Figure 7(a) and Figure 8(a) show the superimposed step response of the system with and without the application of the optimized PID controllers for an amplifier gain of 100, 150 and 200, respectively. While Figure 6(b), Figure 7(b) and Figure 8(b) show their respective cost function minimization.

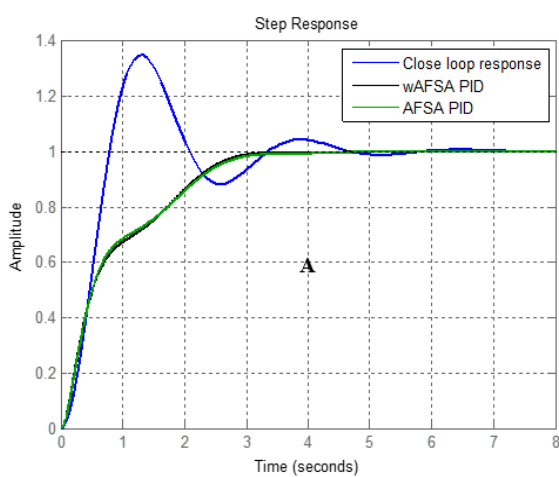

Fig.6(a). Response of the system for an amplifier gain of 100

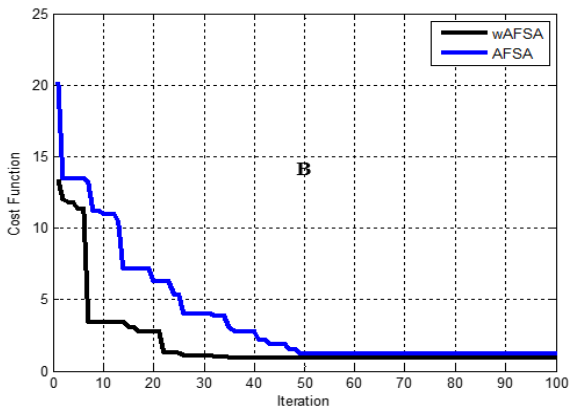

Fig.6(b). Response of the system for an amplifier gain of 100

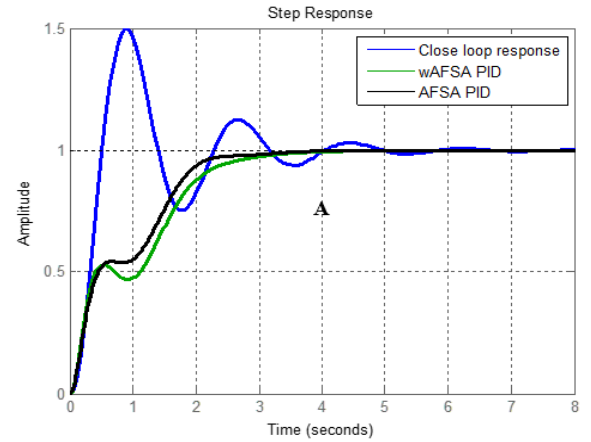

Fig.7(a). Response of the system for an amplifier gain of 150

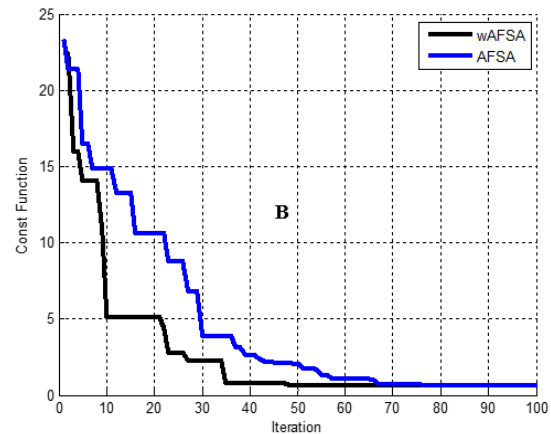

Fig.7(b). Response of the system for an amplifier gain of 150

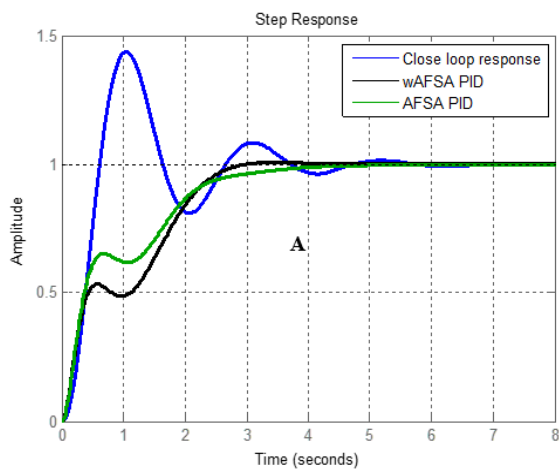

Fig.8(a). Response of the system for an amplifier gain of 200 


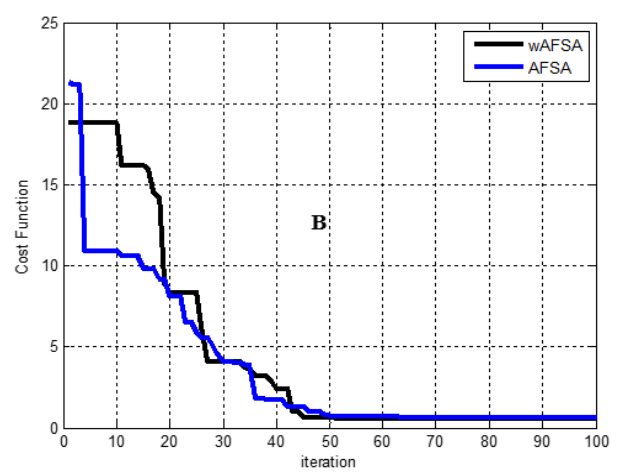

Fig.8(b). Response of the system to an amplifier gain of 200

Table 2 shows the performance comparison of these responses. The cost function is efficiently minimized to a value below 1 using the modified AFSA (Table 2). Even the performance of the modified algorithm appears to be better; the standard algorithm also performed efficiently within the desired design specification. In both cases, the antenna system seems to settle faster for lower amplifier gain. However, the system performance is more optimal for amplifier gain of 100. For example, the cost function, RT, and ST is slightly better when compared with the result of 150 and 200 amplifiers. Also, the step response of the system under an amplifier gain of 150 and 200 exhibits peaking behavior at the transient state. This behavior is an indication that, although the performance of the system under these amplifiers gain (150 and 200) is highly efficient, the system may exhibit a cranky behavior at start-up.

TABle 2: Performance EVAluation

\begin{tabular}{|c|c|c|c|c|c|c|c|}
\hline \multirow{3}{*}{$S / N$} & \multirow{3}{*}{ Parameters } & \multicolumn{6}{|c|}{ Value } \\
\hline & & \multicolumn{2}{|c|}{ Amplifier Gain=100 } & \multicolumn{2}{|c|}{ Amplifier Gain $=150$} & \multicolumn{2}{|c|}{ Amplifier Gain=200 } \\
\hline & & wAF & AFSA & wAF & AFSA & wAF & AFSA \\
\hline \multirow[t]{3}{*}{1} & $\mathrm{~K}_{\mathrm{p}}$ & 0.0930 & 0.0412 & 0.02110 & 0.29862 & 0.0374 & 0.0721 \\
\hline & $\mathrm{K}_{\mathrm{i}}$ & 1.000 & 1.000 & 1.000 & 1.020 & 1.00 & 1.000 \\
\hline & $\mathrm{K}_{\mathrm{d}}$ & 0.2905 & 0.3101 & 0.2735 & 0.22063 & 0.2073 & 0.634 \\
\hline 2 & Cost Function & 0.79238 & 1.0756 & 0.81494 & 1.8004 & 0.87362 & 1.8917 \\
\hline 3 & Rise Time & 0.4039 & 1.6574 & 1.5484 & 1.9924 & 0.2849 & 1.5692 \\
\hline 4 & Settling Time & 2.1644 & 2.3876 & 2.2425 & 2.7568 & 2.5187 & 2.5669 \\
\hline 5 & Overshoot & 0 & 0 & 0 & 0 & 0 & 0 \\
\hline 6 & Steady State Error & 0 & 0 & 0 & 0 & 0 & 0 \\
\hline 7 & Peak Time & 2.9763 & 3.2573 & 5.0895 & 5.1025 & 2.4928 & 2.8180 \\
\hline
\end{tabular}




\section{CONCLUSION}

In this study, we presented an optimization approach for determining the optimized values of PID controller gain for deep space antenna positioning using wAFSA. Some MATLAB simulations were performed and results which were compared with the standard AFSA, show that the proposed approach is efficient with a suitable ST, no OS, reduced RT and most importantly minimized cost. The performance of the optimized controller was evaluated under different deep space antenna amplifier gain (100, 150 and 200) to determine its effectiveness further. Simulation results also confirmed the efficiency of the proposed controller under the selected gains. In our ongoing study, the performance of the developed wAFSA based PID controller will be assessed using a more complex system like the stabilization and control of quadruple inverted pendulum and double quadruple inverted pendulum proposed by $\mathrm{X}$ et al. [28]. Interested researchers can consider a dynamic approach for determining the suitable antenna gain for a particular antenna azimuth condition.

\section{REFERENCES}

[1] J. Gao, J. Wang, and Z. Xie, "Decomposed selected mapping for peak-to-average power ratio reduction in MIMO-OFDM systems," in International Conference on Signal Processing Proceedings, ICSP, 2008, pp. 1900-1903.

[2] W. Gawronski, Modeling and Control of Antennas and Telescopes: Springer Science \& Business Media, 2008.

[3] N. S. Nise, Control Systems Engineering, (With Cd): John Wiley \& Sons, 2007.

[4] S. Agrawal, V. Kumar, K. P. S. Rana, and P. Mishra, "Optimization of PID controller with first order noise filter," in Futuristic Trends on Computational Analysis and Knowledge
Management (ABLAZE), 2015 International Conference on, 2015, pp. 226-231.

[5] M. R. P. Pillai, S. P. Jadhav, and D. M. D. Patil, "Tuning of PID Controllers using Advanced Genetic Algorithm," in International Conference \& Workshop On Advance Computing, 2013.

[6] E. Mirzaei and H. Mojallali, "Auto tuning PID controller using chaotic PSO algorithm for a Boost converter," in Fuzzy Systems (IFSC), 2013 13th Iranian Conference on, 2013, pp. 1-6.

[7] M. Sarlak, M. Tavakoli, and M. Sepehri, "Design of Model Predictive Controller for Trajectory Tracking of a Ground Station Antenna," The Modares Journal of Electrical Engineering, vol. 12, pp. 23-31, 2016.

[8] R. Eberhart and J. Kennedy, "New optimizer using particle swarm theory," in Proceedings of the 1995 6th International Symposium on Micro Machine and Human Science, Piscataway, NJ, United States Nagoya, Jpn, 1995, pp. 39-43.

[9] D. Karaboga and B. Basturk, "A powerful and efficient algorithm for numerical function optimization: artificial bee colony (ABC) algorithm," Journal of global optimization, vol. 39, pp. 459-471, 2007.

[10] X.-S. Yang, "Firefly algorithm, stochastic test functions and design optimisation," International Journal of Bio-Inspired Computation, vol. 2, pp. 78-84, 2010.

[11] M. Dorigo, V. Maniezzo, and A. Colorni, "Ant system: optimization by a colony of cooperating agents," Systems, Man, and Cybernetics, Part B: Cybernetics, IEEE Transactions on, vol. 26, pp. 29-41, 1996.

[12] K. M. Passino, "Biomimicry of bacterial foraging for distributed optimization and control," Control Systems, IEEE, vol. 22, pp. 52-67, 2002.

[13] X. Li, Z. Shao, and J. Qian, "An optimization searching model based on animal autonomous body: Artificial Fish Swarm Algorithm, system engineering theory and practice," 2002.

[14] M. B. Mu'azu, A. T. Salawudeen, T. H. Sikiru, A. Muhammad, and A. I. Abdu., "weighted Artificial Fish Swarm Algorithm with Adaptive Behaviour Based Linear Controller Design for Nonlinear Inverted Pendulum," Jounal of Engineering Research JER, vol. 20, pp. 1-12, March, 20152015. 
[15] A. T. Salawudeen and M. B. Mu'azu, "Stabilization of Inverted Pendulum System using Intelligent Linear Quadratic Regulator Controller," in 7th International Joint Conference on Computational Intelligence, Lisbon Portugal, 2015, pp. 325-333.

[16] Y. S. Cho, W. Y. Yang, J. Kim, and C.-G. Kang, Mimo-Ofdm Wireless Communications With Matlab vol. 1. Singapore: Publisher, John Wiley \& Sons (Asia) Pte Ltd, 2010.

[17] O. A. M. Ali, A. Y. Ali, and B. S. Sumait, "Comparison between the Effects of Different Types of Membership Functions on Fuzzy Logic Controller Performance," International Journal, vol. 76, 2015.

[18] L. A. Alwal, P. K. Kihato, and S. I. Kamau, "DC Servomotor-based Antenna Positioning Control System Design using PID and LQR Controller," in Proceedings of Sustainable Research and Innovation Conference, 2016, pp. 30-35.

[19] B. Allaoua and B. Mebarki, "Intelligent PID DC Motor Speed Control Alteration Parameters Using Particle Swarm Optimization," Artificial Intelligence Resources in Control and Automation Engineering, p. 3, 2012.

[20] B. Allaoua, B. Gasbaoui, and B. Mebarki, "Setting up PID DC motor speed control alteration parameters using particle swarm optimization strategy," Leonardo Electronic Journal of Practices and Technologies, vol. 14, pp. 19-32, 2009.

[21] K. H. Ang, G. Chong, and Y. Li, "PID control system analysis, design, and technology," Control Systems Technology, IEEE Transactions on, vol. 13, pp. 559-576, 2005.

[22] A. Popov, A. Farag, and H. Werner, "Tuning of a PID controller using a multi-objective optimization technique applied to a neutralization plant," in Decision and Control, 2005 and 2005 European Control Conference. CDC-ECC'05. 44th IEEE Conference on, 2005, pp. 7139-7143.
[23] A. T. Salawudeen, "Development of an Improved Cultural Artificial Fish Swarm Algorithm with Crossover," Master of Science Thesis, Department of Electrical and Computer Engineering, Ahmadu Bello University Zaria, Nigeria., Kubani, 2015.

[24] Y. Wu, X. L. Huang, X. Z. Gao, and K. Zenger, "Cultural artificial fish-swarm optimization algorithm and application in the parameters identification of rotor system," Dianji yu Kongzhi Xuebao/Electric Machines and Control, vol. 16, pp. 102-108, 2012.

[25] M. AwadEl-bayoumy, M. Rashad, M. Elsoud, and M. El-dosuky, "FAFSA: Fast Artificial Fish Swarm Algorithm," 2013.

[26] Y. Wu, X. Z. Gao, and K. Zenger, "Knowledgebased Artificial Fish-Swarm algorithm," in 18th IFAC World Congress, Milano, 2011, pp. 14705-14710.

[27] Y. Wang and L. Li, "AN IMPROVED INTELLIGENT ALGORITHM BASED ON THE GROUP SEARCH ALGORITHM AND THE ARTIFICIAL FISH SWARM ALGORITHM," Int. J. Optim. Civil Eng, vol. 5, pp. 37-52, 2015.

[28] A. Muhammad, "Modeling, Simulation and Stabilization of a Double Quad Inverted Pendulum System (DQIP) Using a Linear Quadratic Regulator (LQR) Controller.," Master of Science Degree Thesis, Department of Electrical and Computer Engineering, Ahmadu Bello University Zaria, Nigeria., Unpublished, 2014.

[29] L. M. Paulsen, M. J. Buckley, J. B. West, and J. D. Wolf, "Electronically steerable SATCOM antenna," ed: US Patent 9,337,536, 2016.

[30] S. M. Reddy, P. M. arjuna Rao, B. Madhav, M. Q. Duong, A. Dolara, F. Grimaccia, et al., "Antenna and Propagation (IRECAP)," 2015.

[31] D. Yazdani, B. Saman, A. Sepas-Moghaddam, F. Mohammad-Kazemi, and M. Reza Meybodi, "A new algorithm based on improved artificial fish swarm algorithm for data clustering," International Journal of Artificial Intelligence, vol. 11, pp. 193-221, 2013. 


\author{
المتحكم التفاضلي_التكاملي-المتناسب الأمثل لهوائي فضائي عميق لموتور تيار مستمر عن طريق استخدام تعديل

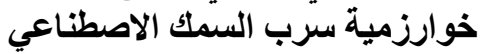

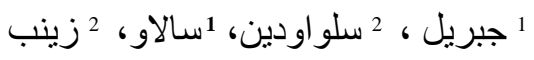 \\ I قسم الهنسة الكهربائية وهندة الحاسبات، جامعة أحدو بيلو زاريا، نيجيريا. \\ 2 قسم الفيزياء، جامعة الاتحادية وكوجا، كوجى الدولة، نيجيريا.
}

الملخص:

الهدف الرئيسي من هذه الورقة هو نطوير وحدة الدتحكم التفاضلي-التكاملي-المتناسب (PID ) الذكي للتحكم في وضع هو ائي فضائي عميق باستخدام خوارزمية سرب السمك الاصطناعي المعلة. المتحكم التناسبي، التكاملي، التفاضلي (PID) لا يزال الأكثر استخداما على نطاق واسع في الصناعات الهندسية نظر السهولة تنفيذه وينطلب تدخلات ضئيلة أو معدومة من المصد. أداء المتحم يعتدد إلى حد كبير على اختيار معاملات وحدة التحكم (التناسبي ، التكاملي ، التفاضلي). باستخدام الطريق التقليدية، قد يستغرق عدة ساعات أو حتى أيام للحصول علي مجموعة من المعاملات التي تعطي مواصفات النظام المطلوبة. يعرض هذا البحث الطريقة المثلي لتحديد معاملات المتحكم PID للسيطرة على وضع هوائي فضائي عميق باستخدام تعديل خوارزمية سرب السمك الاصطناعي (wAFSA). تم أيضا استخدام خوارزمية سرب السمك الاصطناعي التقليدية بدون تعديل لغرض المقارنة. تم تتفيذ عدد من برامج المحاكاة باستخدام MATLAB للهو ائي الفضائي العميق لعدة معاملات تكبير مختلفة لتحديد المتحكم المقترح. وتبين من نتائج المحاكاة فعالية وصلاحية وحدة تحكم PID الأمثل المقتر من حيث زمن الاستقرار و زمن الارتفاع، الارتفاع الأقصى، الخطأ في الحالة المستقرة والأكثر أهمية وهو تقليل 